\title{
Effectiveness of an Intervention to Enhance Occupational Physicians' Guideline Adherence on Sickness Absence Duration in Workers with Common Mental Disorders: A Cluster- Randomized Controlled Trial
}

\author{
Karlijn M. van Beurden ${ }^{1}$ Evelien P. M. Brouwers ${ }^{1} \cdot$ Margot C. W. Joosen $^{1}$ • \\ Michiel R. de Boer $^{2} \cdot$ Jaap van Weeghel $^{1,3,4} \cdot$ Berend Terluin $^{5} \cdot$ Jac J. L. van der Klink ${ }^{1,6}$
}

Published online: 30 November 2016

(c) The Author(s) 2016. This article is published with open access at Springerlink.com

\begin{abstract}
Purpose Evidence-based guidelines in occupational health care improve the quality of care and may reduce sickness absence duration. Notwithstanding that, guideline adherence of occupational physicians (OPs) is limited. Based on the literature on guideline implementation, an intervention was developed that was shown to effectively improve self-reported adherence in OPs. The aim of present study was to evaluate whether this intervention leads to earlier return to work (RTW) in workers with common mental disorders (CMD). Methods In a twoarmed cluster randomized controlled trial, 66 OPs were randomized. The trial included 3379 workers, with 1493 in the intervention group and 1886 in the control group. The outcome measures were: time to full RTW, time to first RTW, and total hours of sickness absence. Cox regression analyses and generalized linear mixed model analyses were
\end{abstract}

Evelien P. M. Brouwers

e.p.m.brouwers@tilburguniversity.edu

1 Department of Social and Behavioral Sciences, Tranzo Scientific Center for Care and Welfare, Tilburg University, PO Box 90153, 5000 LE Tilburg, The Netherlands

2 Department of Health Sciences, Faculty of Earth and Life Sciences, VU University Amsterdam, De Boelelaan 1085, 1081 HV Amsterdam, The Netherlands

3 Phrenos Centre of Expertise, PO Box 1203, 3500 BE Utrecht, The Netherlands

4 Parnassia Group, Dijk en Duin Mental Health Center, PO Box 305, 1900 AH Castricum, The Netherlands

5 Department of General Practice and Elderly Care Medicine, EMGO Institute for Health and Care Research, VU University Medical Center Amsterdam, PO Box 7057, 1007 MB Amsterdam, The Netherlands

6 Netherlands School of Public \& Occupational Health, PO Box 20022, 3502 LA Utrecht, The Netherlands used for the evaluations. Results The median time to RTW was 154 days among the 3228 workers with CMD. No significant differences occurred in (time to) full RTW between intervention and control group HR 0.96 (95\% CI 0.81-1.15) nor for first RTW HR 0.96 (95\% CI 0.80-1.15). The mean total hours of sickness absence was $478 \mathrm{~h}$ in the intervention group and $483 \mathrm{~h}$ in the control group. Conclusions The intervention to enhance OPs' guideline adherence did not lead to earlier RTW in workers with CMD guided by the OPs. Possible explanations are the remaining external barriers for guideline use, and that perceived guideline adherence might not represent actual guideline adherence and improved care.

Trail registration: ISRCTN86605310.

Keywords Mental health - Occupational health service Occupational medicine $\cdot$ Practice guideline $\cdot$ Return to work

$\begin{array}{ll}\text { Abbreviations } \\ \text { CMD } & \text { Common mental disorders } \\ \text { NVAB } & \text { Netherlands Society of Occupational Medicine } \\ \text { RTW } & \text { Return to work } \\ \text { OP } & \text { Occupational physician } \\ \text { RCT } & \text { Randomized controlled trial } \\ \text { OHS } & \text { Occupational health service } \\ \text { ICD-10 } & \text { International Classification of Diseases version } \\ & 10\end{array}$

\section{Introduction}

As in many Western countries, in the Netherlands, sickness absence due to common mental disorders (CMD) is a problem that is associated with individual suffering and 
high costs for employers and society [1-3]. To improve the quality of occupational care, the Netherlands Society of Occupational Medicine (NVAB) developed (2000) and revised (2007) an evidence-based practice guideline named "Management of mental health problems of workers by occupational physicians" [4, 5]. Several studies have since been conducted on the effect of interventions aiming to improve the use of this guideline by occupational physicians (OPs) on workers outcomes. The first study, by van der Klink et al. [6] showed positive effects on the time to return to work (RTW); in this study, the occupational physicians were compliant with the intervention. In a retrospective study, researchers found that closer adherence to this guideline was associated with shortened sickness absence in workers with adjustment disorders [7]. In addition, Rebergen et al. found that OPs actual adherence to the guideline was limited, despite the fact that they had a positive attitude about using this guideline [8-10]. Apparently, implementing this guideline in practice is still challenging.

To improve adherence to this guideline, we developed a tailored implementation strategy based on findings from scientific implementation literature on how to improve guideline adherence [11-15]. According to the literature, more active implementation strategies are needed [12, 13] rather than dissemination among professionals and short introductions. Preferably, these active implementation strategies are tailored for a specific target group and setting, and they intend to eliminate perceived barriers that hinder physicians from using guidelines $[11,14,16]$. Moreover, to successfully overcome barriers for guideline use, the target users of a guideline should be actively involved in identifying barriers for specific guideline recommendations and selecting solutions [15]. In line with this aim, we developed an intervention to enhance OPs' guideline adherence, focusing on identifying and solving the barriers for applying this guideline's key recommendations. This intervention showed to be feasible in practice and effective in enhancing OPs' knowledge, attitudes, perceived skills, and perceived guideline adherence; however, their perceived external barriers remained [17].

In the present cluster randomized controlled trial (RCT), we evaluated the tailored intervention to see whether it led to earlier and sustained RTW in workers who were sicklisted due to CMD compared to those receiving usual care. Specifically, we formulated the following research questions: What is the effect of the intervention aimed to enhance OPs' guideline adherence on (1) the time to full RTW, (2) the time to first RTW in workers sick-listed due to CMD, (3) the total hours of sickness absence during a 1 year period after the start of the sickness absence?

\section{Methods}

In the present paper, the "CONSORT 2010 statement: extension to cluster randomized controlled trials" [18] was used for reporting. A detailed description of the study protocol [19] and the intervention for OPs have been reported elsewhere [17].

\section{Study Context}

According to the Dutch Gatekeeper Improvement Act, in case of sickness absence, both employer and worker are responsible for the recovery and return to work of the sick listed worker [20]. The employer is obliged to pay at least $70 \%$ of the wage during the sickness absence of a worker for a period of 2 years and to provide occupational health care. Sick listed workers have to consult an OP for diagnosis, assessment of the workability, and guidance within the first 6 weeks of the recovery and return to work process [20]. The OP has to manage this process with workers and their employer and supervisor.

\section{Trial Design}

This study was designed as a two-armed cluster RCT with randomization at the level of the OP (Fig. 1).

The OPs were randomly allocated to the intervention group or to the control group. After completion of the 1 year intervention for the OPs, the registration of data on sickness absences and workers' RTW was started from January 1st, 2012 until February 28th, 2014. The data were routinely recorded by the occupational health service (OHS) in their registration system, and for this study the data were extracted by the OHS from their registration system. The data provided to us were not traceable to the individual workers.

We obtained approval from the Medical Research Ethics Committee of St. Elisabeth Hospital in Tilburg, The Netherlands. This study was registered in the ISTCTN trial register, ISRCTN86605310.

\section{Participants}

\section{Occupational physicians}

OPs were recruited between October 2010 and January 2011 from sites of a large OHS in the Netherlands. All 155 OPs of the sites in the Southern part of The Netherlands received written and oral information about the study. The 66 OPs participated on a voluntary basis and signed informed consents. After completing the intervention, the OPs in the intervention group received educational credits. 


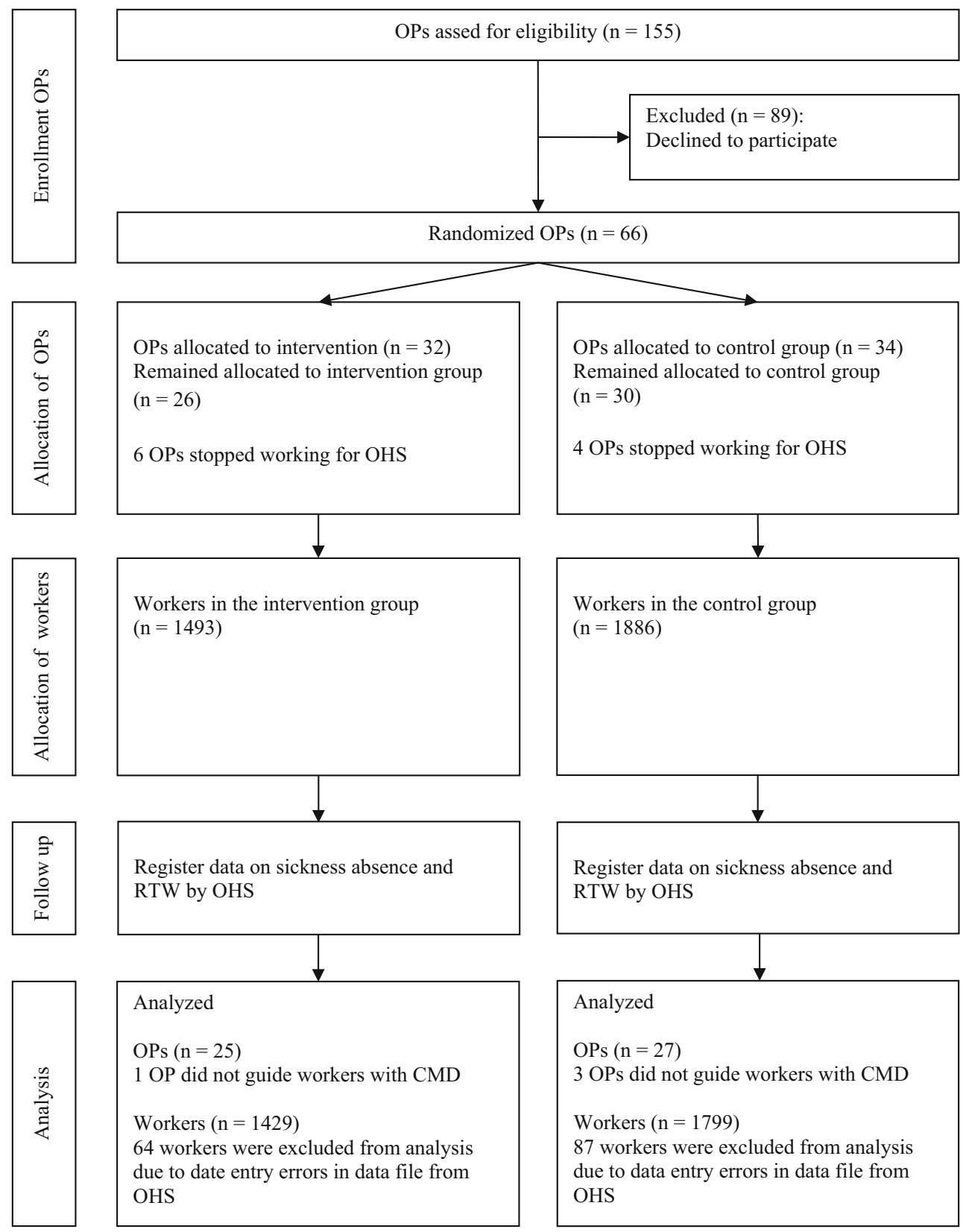

OP: Occupational physician; OHS: Occupational Health Service; RTW: Return to work; CMD: Common Mental Disorders

Fig. 1 Flow diagram of this study

\section{Workers}

Eligible workers were between 18 and 64 years old, and had a first period of sickness absence between January 1st, 2012 and January 15th, 2013. All workers were receiving guidance by an OP who participated in the study and who had diagnosed the worker as having CMD (according to the Dutch Classification of Diseases, based on the ICD-10) [21]. The companies that workers were employed at, varied in size and served different sectors.

\section{Intervention}

\section{Intervention Group}

Workers in the intervention group received guidance from an OP who had received the intervention to enhance OPs' guideline adherence. A detailed description of this intervention has been published elsewhere [17]. In short, this intervention consists of an eight-session training in small peer-learning groups, takes place over 12 months, and is 
focused on barriers that hindered OPs from using specific recommendations in this guideline in practice. According to the model of Cabana et al. [22], guideline adherence can be affected by three main clusters of barriers: (1) lack of knowledge, (2) negative attitudes, and (3) external barriers. The OPs exchanged ideas and solutions to overcome the perceived barriers, drew up joint action plans on how to implement these solutions in their daily practice, and tested the suggested solutions in daily practice $[17,19]$.

Regarding the guideline content, the overall role of the OP is to monitor the process of sickness absence and RTW, to facilitate communication between workers and their employer and supervisor, to provide information and advice to the employer, supervisor, human resource management, and co-workers on how to support the worker and enhance his or her recovery and RTW, and to intervene in case of stagnation, either by OPs' own interventions or by referral to a mental health specialist. According to the guideline, the guidance of a worker who is sick-listed with CMD starts with a problem orientation and an OP's diagnosis. Next, the OP evaluates the worker's recovery and RTW process by monitoring and enhancing the worker's problem solving capacity according to the three phase model of Meichenbaum [23]. If the recovery process stagnates, the OP uses cognitive behavioral techniques to enhance the worker's problem-solving capacity. Consultations with the worker take place every 3 weeks during the first 3 months, and then every 6 weeks thereafter. The OP contacts the supervisor or employer once a month [4, 24]. A detailed description of the content of the guideline has been reported elsewhere [17, 19, 25].

\section{Control Group}

As the guideline was distributed among Dutch OPs and became part of their medical education, guideline-based care came to be seen as usual care. However, subsequent research has shown that actual adherence to this guideline was limited [7-10]; therefore, in this study, care as usual was the guidance received by workers in the control group.

\section{Outcomes}

The focus of the present study was on outcomes at the level of the workers. Workers' personal baseline characteristics (age, gender, number of contract working hours per week), and data on sickness absence and RTW were extracted from the OHS registration system.

\section{Primary Outcome}

The time to the CMD workers' full RTW was calculated as the number of calendar days between the first day of sickness absence and the first day of full RTW. Working the number of hours of their employment contract, for at least 4 weeks was considered a full RTW. The calculated time until full RTW was based on the data extracted from the OHS registration system.

\section{Secondary Outcomes}

Two secondary outcomes were assessed, i.e. time to first RTW and the total number of sick-leave hours. The time to the first RTW was calculated as the number of calendar days between the first day of sickness absence and the first day of RTW, irrespective of the number of working hours resumed in a week and the duration of this period. The total number of sick leave hours was calculated over a 1-year period, taking into account the total hours of their employment contract and partial RTW.

\section{Sample Size}

We performed a power analysis to determine the sample size needed to detect a difference between the control and the intervention group with respect to the time to the CMD workers' full RTW (primary outcome) and calculated the need to include a total of 232 workers (A detailed description of the performed sample size was published elsewhere [19]). Despite considerable efforts the recruitment of a representative group of workers was difficult for several reasons, e.g. employers gave no permission to invite their workers for the study or eligible workers were too tired to want to participate. Because recruitment resulted in too small a sample size, we subsequently used the anonymized sickness absence and RTW data of all 3379 workers sick listed due to CMD, who were guided by participating OPs during the study period. These data had already been recorded in the OHS registration system. This way, resulted in an unbiased and much larger data set. A consequence of using the anonymized data of 3379 workers was the limited number of available baseline characteristics, such as diagnosis, severity of CMD, aspects related to the work context, and treatment by other (mental) health care professionals that preferably would have been taken into account as possible confounders or effect modifiers in the analyses. The data of the 128 recruited workers will be used in other evaluations, separate from the current paper.

\section{Randomization}

After recruitment, OPs were randomized by computerized allocation to the intervention or to the control group. The allocation was communicated to the OPs after the randomization of all participating OPs. Workers were allocated to the same group as their OP. 


\section{Blinding}

Workers and their companies were blinded for randomization since they were not aware of the allocation of their OP. The data collector who extracted the data from the registration system at the OHS and the researcher who assessed the survival outcomes $(\mathrm{MdB})$ were also blinded for allocation of the OPs and of the workers to the intervention or to the control group. OPs were not informed about the inclusion of the workers they guided.

\section{Statistical Methods}

\section{Time Until Full RTW and Time Until First RTW}

To evaluate the effect of the intervention, we performed intention-to-treat analyses. To illustrate the differences between the intervention and control group, we generated Kaplan-Meier survival curves, but for practical reasons, did not account for the multilevel design. Cox regression analysis was used to compare the difference between the intervention and the control group on the (time until) full and first RTW. To correct for the cluster design, we used the frailty random effect in this analysis [26]. Cox regression models the logarithm of the incidence or hazard rate, the number of new 'events' (i.e. RTW) per population 'at-risk' (i.e. sick-listed workers) per unit time. Workers were censored when the full RTW or the first RTW was not established within the follow up period (from the first day of sickness absence until February 28th 2014), or when the worker was lost to follow up within that period. The influence of baseline characteristics was evaluated using gender, age, and number of working hours as covariates in the model.

\section{Total Hours of Sickness Absence}

To evaluate the total hours of workers' sickness absence, we used generalized linear mixed models analysis with inverse Gaussian distribution. The total hours of workers' sickness absence was the dependent variable. Group (intervention of control group) was added as a fixed factor to the model.

Analyses were performed with $\mathrm{R}$ statistical program version 3.0.1 with the frailtypack [26] and SPSS version 19.0 (IBM Corp., Armonk, NY, 2010).

\section{Results}

\section{Participant Flow and Baseline Data}

A total of 66 OPs participated. As can be seen in Fig. 1, data of 3228 workers were analyzed, of which 280 workers did not establish full RTW and 214 workers did not establish first RTW within the follow up period. The mean follow up time was 595 days (SD 118) from first day of sick leave until February 28th 2014. Both groups contained more female than male workers. The number of contract working hours per week was comparable between both groups. See Table 1.

\section{Outcomes}

\section{Time Until Full RTW}

The differences in time to full RTW between the two groups are illustrated with the Kaplan-Meier survival curve, see Fig. 2. The number of workers who established full RTW, and the mean and median time until full RTW, were comparable between both groups (see Table 2). The hazard ratio of the intervention compared to the control group was 0.96 (95\% CI 0.81-1.15), indicating that workers in the intervention group and in the control group had the same likelihood of full RTW during the follow-up period. Adjustments for baseline characteristics (age, gender and number of contract working hours per week) yielded a comparable hazard ratio $0.97 \quad(95 \%$ CI 0.82-1.16). As some workers had been treated by several different OPs (e.g. during holidays, or reorganizations), an additional analysis on workers guided by only one OP
Table 1 Baseline characteristics of the participants per group

\begin{tabular}{|c|c|c|c|c|c|c|}
\hline & \multicolumn{3}{|c|}{ Intervention group } & \multicolumn{3}{|c|}{ Control group } \\
\hline & Mean & SD & $\%$ & Mean & $\mathrm{SD}$ & $\%$ \\
\hline Worker characteristic & \multicolumn{3}{|c|}{$(\mathrm{n}=1429)$} & \multicolumn{3}{|c|}{$(\mathrm{n}=1799)$} \\
\hline Gender, male & - & - & 39.5 & - & - & 43.3 \\
\hline Age & 45.1 & 11.1 & - & 44.1 & 10.8 & - \\
\hline Number of contract working hours per week & 29.8 & 10.7 & - & 30.6 & 10.3 & - \\
\hline Occupation physician characteristic & \multicolumn{3}{|c|}{$(\mathrm{n}=25)$} & \multicolumn{3}{|c|}{$(\mathrm{n}=27)$} \\
\hline Gender, male & - & - & 65.4 & - & - & 81.5 \\
\hline Age & 54.0 & 3.9 & - & 54.0 & 5.6 & - \\
\hline
\end{tabular}


( $\mathrm{n}=2796)$ was done, which showed a comparable hazard ratio of 0.99 (95\% CI $0.81-1.20)$.

\section{Time Until First RTW}

The mean and median time to first RTW and the number of workers who established their first RTW within 1 year after the start of the sickness absence were comparable in both groups (see Table 2). The hazard ratio of the intervention compared to the control group was 0.96 (95\% CI 0.80-1.15), indicating that workers in the intervention group and in the control group had the same likelihood of having a first RTW during the follow-up period. Adjustments for baseline characteristics (age, gender, and number

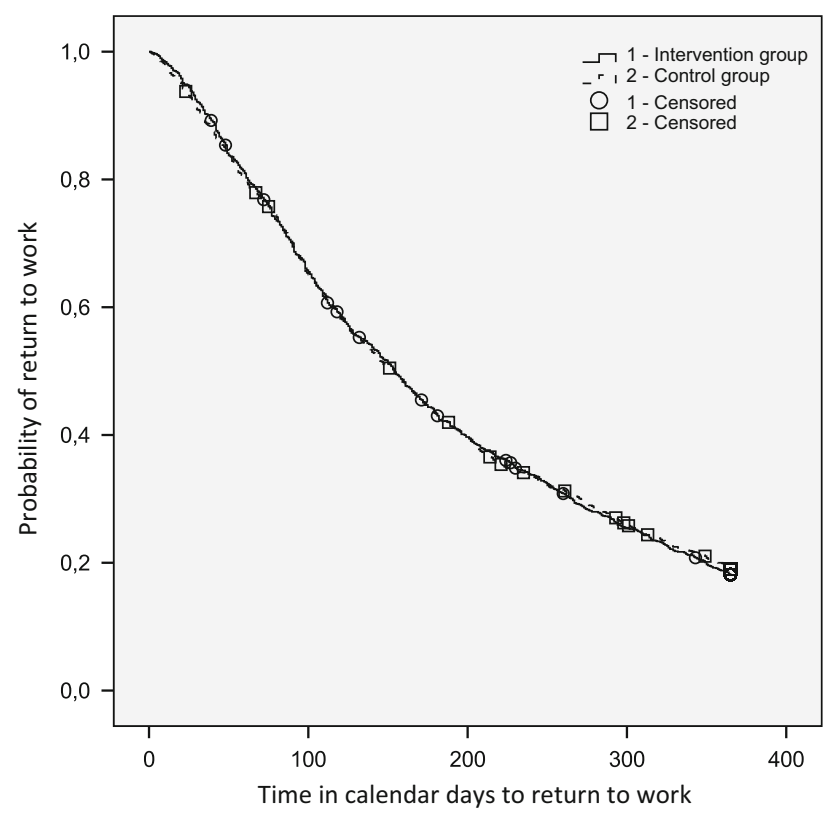

Fig. 2 Kaplan-Meier curve time to full return to work of contract working hours per week) yielded a comparable hazard ratio 0.96 (95\% CI 0.80-1.15). An additional analysis on workers guided by only one OP $(n=2796)$ showed a comparable hazard ratio $1.01 \quad(95 \%$ CI 0.84-1.22).

\section{Total Hours of Sickness Absence}

The estimated mean for total hours of sickness absence was 478 (95\% CI 425-530) in the intervention group and 483 (95\% CI 436-531) in the control group (-5.51 (95\% CI -76 to 65$), p=0.88)$.

\section{Discussion}

Although the intervention had shown to be effective in improving OPs' self-reported guideline adherence [17], the present study showed that it was not effective in reducing the sickness absence duration in workers with CMD. Moreover, no differences were found for the total hours of sickness absence due to CMD in the 12 months after the start of the sick leave.

There are various possible explanations. A first option is that, notwithstanding that we know from the feasibility study that the intervention was completed as planned and that the perceived guideline adherence improved [17], the factual provided care to the workers did not improve. A previous study has shown that self-reported guideline adherence is not an accurate measure of guideline adherence [27], and therefore OPs may have overestimated their own behavior. In addition to the current study, the effect of the intervention on OPs' actual adherence was evaluated, and some improvement of OPs' guideline adherence was found (Joosen et al., submitted). Hence, it is possible that this small improvement did not lead to optimal guidelinebased care by OPs.

Table 2 Return to work outcomes per group

\begin{tabular}{|c|c|c|c|c|c|c|c|c|c|c|}
\hline & \multicolumn{4}{|c|}{ Intervention group } & \multicolumn{4}{|c|}{ Control group } & \multirow[t]{3}{*}{ HR } & \multirow[t]{3}{*}{$95 \% \mathrm{CI}$} \\
\hline & \multicolumn{4}{|c|}{$(\mathrm{n}=1429)$} & \multicolumn{4}{|c|}{$(\mathrm{n}=1799)$} & & \\
\hline & $\%$ & Median & Mean & $\mathrm{SD}$ & $\%$ & Median & Mean & SD & & \\
\hline Full RTW ${ }^{\mathrm{a}}$ after 12 months follow-up & 81 & - & - & - & 81 & - & - & - & - & - \\
\hline Full RTW ${ }^{\mathrm{a}}$ total follow-up & 91 & - & - & - & 89 & - & - & - & - & - \\
\hline Days to full RTW ${ }^{\mathrm{a}}$ & - & - & 212 & 158 & - & - & 214 & 182 & - & - \\
\hline Days to full RTW ${ }^{\mathrm{a}}$ & - & 154 & - & - & - & 154 & - & - & 0.96 & $0.81-1.15$ \\
\hline First $\mathrm{RTW}^{\mathrm{a}}$ after 12 months follow-up & 89 & - & - & - & 87 & - & - & - & - & - \\
\hline First RTW ${ }^{\mathrm{a}}$ total follow-up & 93 & - & - & - & 91 & - & - & - & - & - \\
\hline Days to first RTW ${ }^{\mathrm{a}}$ & - & - & 151 & 173 & - & - & 158 & 185 & - & - \\
\hline Days to first $\mathrm{RTW}^{\mathrm{a}}$ & - & 91 & - & - & - & 93 & - & - & 0.96 & $0.80-1.15$ \\
\hline
\end{tabular}

${ }^{a} R T W$ return to work 
Second, even if OPs' knowledge, attitude or even factual behavior did improve, this might not have led to real improvement because of remaining conditional external barriers [17]. During and after the training OPs perceived many conditional external barriers for guideline use, such as lack of time and lack of facilities to actually follow the guideline. For example, this was due to financial contracts between employers and OHS limiting the number of contacts between OP and worker, and the conflicting policy of and lack of collaboration with for example employer and other (mental) health care providers [28]. Besides, in general OPs experience a high increase of the OPs' workloads [29]. Although the intervention enhanced OPs' knowledge, attitudes, perceived skills, and perceived guideline adherence, it is possible that the remaining conditional external barriers, such as very limited time and possibilities to see the worker, prevented these positive effects to lead to an effective practice.

A third possible explanation is that the guideline in its present form is not effective, and workers need a different kind of guidance in order to return to their work earlier. However, a retrospective study [7] and a process evaluation of a randomized trial [10] showed several elements of the guideline to be significantly related to an earlier RTW [7]. Furthermore, the guideline recommendations are based on and supported by evidence from a variety of studies $[6,30,31]$, such as regarding the fact that relapse prevention is important [32], which makes it unlikely that the guideline is not effective.

In combination with and in addition to the former point a fourth possible explanation is that the contrast between the intervention and the control groups may have been insufficient. A RCT does not reveal absolute effectiveness, but effectiveness relative to the control group. In our study all OPs were not only supposed to work according to the Dutch occupational health guideline, but also, since the introduction of this guideline, the idea has become common among Dutch OPs that earlier work resumption can contribute to recovery, which is a key recommendation in the guideline. This was not yet the case in the late 1990s when the study of van der Klink et al. [6] found their intervention to be effective. The deficiency to find an effect might thus reflect a lack of contrast relative to care as usual that changed considerably in the past 15 years in the Netherlands, rather than an absolute lack of efficiency of the guideline.

A combination of these factors may also be an explanation for the fact that, in spite of many years of research, it seems difficult to develop interventions that are successful in reducing the sickness absence duration in workers with mental health problems. The findings of this study add to a series of RCTs in which interventions were developed to reduce sickness absence duration in workers with CMD
[33-36]. Most of these studies were conducted in The Netherlands, and the interventions were not effective in reducing workers' sickness absence duration [34-36]. In some previous studies implementation problems interfered with the developed interventions and as such also with the findings on the interventions' effectiveness [34, 36, 37]. Very few previous studies have found a positive effect on sickness absence duration $[6,30,33]$. In all these effective studies OPs could spend time on guidance and contacts with the company. The intervention in one of these studies focused both on occupational professionals and on workers [33], which contrasts with most other interventions that primarily focus on professionals. Moreover, remarkably, in most recent studies, the time to workers' RTW was longlasting [34-36], which might reflect the growing experienced work pressure and demands by Dutch workers [38].

The present study has several strengths and limitations that need to be discussed. A strength of this study was the cluster RCT design, which limited the possibility of contamination between the intervention group and the control group. To prevent selection bias, the workers were selected from the registration system of the OHS after their first consultations with participating OPs. Another strength was the large sample size, of 3379 workers, which made it more likely to have reliable outcomes. The data on these workers were extracted from the OHS registration system to prevent recall bias which could occur in workers with CMD. The drawback of using the OHS registration system for data extraction, was the limited number of baseline characteristics available, such as specific diagnosis and severity, information about the work context, and treatment by other (mental) health care professionals. Preferably, these would have been used as possible confounders or possible effect modifiers in the analyses, providing better explanations for the findings. However, due to the randomized controlled trial design, it expected that these aspects were similar in both groups. Another limitation is the lack of the assessment of OPs' actual guideline adherence that might have given more information to explain the found results. More comprehensive outcomes were collected for the smaller sample of 128 workers and the results of these evaluations will be published separately.

Overall, the intervention developed to enhance OPs' guideline adherence in this study did not reduce the sickness absence duration in workers with CMD. Several possible explanations were given for this lack of effectiveness. Future research should further explore the implementation process and the effect of the implementation strategy on the provided occupational health care, preferably in a mixed methods design. If conditional extern barriers for using the guideline actually impede optimal guideline-based care, than future research should also focus on the organization of occupational health care beside the 
one-sided focus on interventions for occupational professionals. Furthermore, recently a positive effect on RTW was found for a decision aid for OPs combined with an e-health module for workers [33]. Possibly guideline-based care can be improved by providing such tools for occupational professionals and workers. In general, recent studies have shown CMD workers' long-lasting sickness absence duration whereby mental health problems remain a large problem for society. Future research and practice should continue the search on how to solve this problem.

Acknowledgements We would like to thank all OPs and workers for participating in the study. We also thank Remmy Kiers for extracting the data from the OHS registration system and Wobbe Zijlstra for his statistical support and data management of the extracted data. This study was financially supported by The Netherlands Organization for Health Research and Development (ZonMw) (Grant Number 208030001).

Author Contributions $\mathrm{KMvB}$, EPMB, MCWJ, JvW, BT, and JJLvdK contributed to the conception and design of the study. MRdB and $\mathrm{KMvB}$ performed the statistical analyses. $\mathrm{KMvB}$ wrote the manuscript. KMvB, EPMB, MCWJ, MdB, JvW, BT, and JJLvdK revised and commented on the manuscript. All authors read and approved the final manuscript.

\section{Compliance with Ethical Standards}

Conflicts of interest JJLvdK was the manager and main author of the NVAB guideline. JJLvdK did not receive fees for the use of the guideline. $\mathrm{KMvB}, \mathrm{EPMB}, \mathrm{MCWJ}, \mathrm{MRdB}$, BT declare that they have no conflicts of interests.

Open Access This article is distributed under the terms of the Creative Commons Attribution 4.0 International License (http://creative commons.org/licenses/by/4.0/), which permits unrestricted use, distribution, and reproduction in any medium, provided you give appropriate credit to the original author(s) and the source, provide a link to the Creative Commons license, and indicate if changes were made.

\section{References}

1. OECD. Sick on the Job. Myths and Realities about Mental Health and Work. In: The OECD Mental Health and Work Project. OECD. 2011. http://www.oecd.org/els/emp/sickonthejob2011. htm. Accessed 14 April 2014.

2. Dekkers-Sánchez PM, Hoving JL, Sluiter JK, Frings-Dresen MHW. Factors associated with long-term sick leave in sick-listed employees: a systematic review. Occup Environ Med. 2008;65(3):153-7. doi:10.1136/oem.2007.034983.

3. Henderson M, Glozier N, Holland Elliott K. Long term sickness absence is caused by common conditions and needs managing. BMJ. 2005;330(7495):802-3. doi:10.1136/bmj.330.7495.802.

4. van der Klink JJL, Ausems CMM, Beijderwellen BD, Blonk R, Bruinvels DJ, Dogger J et al. Richtlijn: Handelen van de berdijfsarts bij werkenden met psychische problemen, herziene versie [Guideline: The management of mental health problems of workers by occupational physicians; revised version]. Utrecht: NVAB [Netherlands Society of Occupational Medicine]; 2007.

5. van der Klink JJL ea. Richtlijn: Handelen van de bedrijfsarts bij werkenden met psychische problemen [Guideline: The management of mental health problems of workers by occupational physicians]. Eindhoven: NVAB [Netherlands Society of Occupational Medicine]; 2000.

6. van der Klink JJ, Blonk RW, Schene AH, van Dijk FJ. Reducing long term sickness absence by an activating intervention in adjustment disorders: a cluster randomised controlled design. Occup Environ Med. 2003;60(6):429-37.

7. Nieuwenhuijsen K, Verbeek JHAM, Siemerink JCMJ, TummersNijsen D. Quality of rehabilitation among workers with adjustment disorders according to practice guidelines; a retrospective cohort study. Occup Environ Med. 2003;60(suppl 1):i21-5. doi:10.1136/oem.60.suppl_1.i21.

8. Rebergen D, Hoenen J, Heinemans A, Bruinvels D, Bakker A, van Mechelen W. Adherence to mental health guidelines by Dutch occupational physicians. Occup Med. 2006;56(7):461-8. doi:10.1093/occmed/kq1042.

9. Rebergen DS, Bruinvels DJ, Bezemer PD, van der Beek AJ, van Mechelen W. Guideline-based care of common mental disorders by occupational physicians (CO-OP study): a randomized controlled trial. J Occup Environ Med/Am Coll Occup Environ Med. 2009;51(3):305-12. doi:10.1097/JOM.0b013e3181990d32.

10. Rebergen DS, Bruinvels DJ, Bos CM, van der Beek AJ, van Mechelen W. Return to work and occupational physicians' management of common mental health problems-process evaluation of a randomized controlled trial. Scand J Work Environ Health. 2010;36(6):488-98.

11. Lugtenberg M, Burgers JS, Westert GP. Effects of evidencebased clinical practice guidelines on quality of care: a systematic review. Qual Saf Health Care. 2009;18(5):385-92. doi:10.1136/ qshc.2008.028043.

12. Grol R, Grimshaw J. From best evidence to best practice: effective implementation of change in patients' care. Lancet. 2003;362(9391):1225-30. doi:10.1016/s0140-6736(03)14546-1.

13. Bero LA, Grilli R, Grimshaw JM, Harvey E, Oxman AD, Thomson MA. Closing the gap between research and practice: an overview of systematic reviews of interventions to promote the implementation of research findings. The Cochrane Effective Practice and Organization of Care Review Group. BMJ. 1998;317(7156):465-8.

14. Davis D, O'Brien MA, Freemantle N, Wolf FM, Mazmanian P, Taylor-Vaisey A. Impact of formal continuing medical education: do conferences, workshops, rounds, and other traditional continuing education activities change physician behavior or health care outcomes? JAMA. 1999;282(9):867-74.

15. Bosch M, van der Weijden T, Wensing M, Grol R. Tailoring quality improvement interventions to identified barriers: a multiple case analysis. J Eval Clin Pract. 2007;13(2):161-8. doi:10. 1111/j.1365-2753.2006.00660.x.

16. Lugtenberg M, Zegers-van Schaick JM, Westert GP, Burgers JS. Why don't physicians adhere to guideline recommendations in practice? An analysis of barriers among Dutch general practitioners. Implement Sci. 2009;4:54. doi:10.1186/1748-5908-4-54.

17. Joosen MC, van Beurden KM, Terluin B, van Weeghel J, Brouwers EP, van der Klink JJ. Improving occupational physicians' adherence to a practice guideline: feasibility and impact of a tailored implementation strategy. BMC Med Educ. 2015;15(1):82. doi:10.1186/s12909-015-0364-8.

18. Campbell MK, Piaggio G, Elbourne DR, Altman DG. Consort 2010 statement: extension to cluster randomised trials. BMJ. 2012;345:e5661. doi:10.1136/bmj.e5661.

19. van Beurden KM, Brouwers EP, Joosen MC, Terluin B, van der Klink JJ, van Weeghel J. Effectiveness of guideline-based care by occupational physicians on the return-to-work of workers with common mental disorders: design of a cluster-randomised controlled trial. BMC Public Health. 2013;13:193. doi:10.1186/14712458-13-193. 
20. Korthals AH. Wet verbetering poortwachter. [Dutch Gatekeeper Improvement Act]. In: Wet- en regelgeving. Ministerie van Justitie, Den Haag. 2001. http://wetten.overheid.n1/BWBR 0013063. Accessed 22 Dec 2014.

21. World Health Organization. International Statistical Classification of Diseases and Related Health Problems-10th revision, edition 2010. Geneva: WHO; 2011.

22. Cabana MD, Rand CS, Powe NR, Wu AW, Wilson MH, Abboud PA, et al. Why don't physicians follow clinical practice guidelines? A framework for improvement. JAMA. 1999;282(15): 1458-65.

23. Meichenbaum DH, Caneron R. Stress inoculation training. In: Meichenbaum DH, Jarenko ME, editors. Stress reduction and Prevention. New York: Plenum Press; 1983. p. 115-54.

24. van der Klink JJ, van Dijk FJ. Dutch practice guidelines for managing adjustment disorders in occupational and primary health care. Scand J Work Environ Health. 2003;29(6):478-87.

25. van Beurden KM, van der Klink JJ, Brouwers EP, Joosen MC, Mathijssen JJ, Terluin B, et al. Effect of an intervention to enhance guideline adherence of occupational physicians on return-to-work self-efficacy in workers sick-listed with common mental disorders. BMC Public Health. 2015;15(1):796. doi:10. 1186/s12889-015-2125-3.

26. Rondeau V, Mazroui Y, Gonzalez J. Frailtypack: an R package for the analysis of correlated survival data with frailty models using penalized likelihood estimation or parametrical estimation. J Stat Softw. 2012;47(4):1-28.

27. Adams AS, Soumerai SB, Lomas J, Ross-Degnan D. Evidence of self-report bias in assessing adherence to guidelines. Int J Qual Health Care: J Int Soc Qual Health Care/ISQua. 1999;11(3): 187-92.

28. Lugtenberg M, van Beurden KM, Brouwers EP, Terluin B, van Weeghel J, van der Klink JJ, et al. Occupational physicians' perceived barriers and suggested solutions to improve adherence to a guideline on mental health problems: analysis of a peer group training. BMC health services research. 2016;16:271. doi:10. 1186/s12913-016-1530-3.

29. SER. Betere zorg werkenden. Een visie op de toekomst van de arbeidsgerelateerde zorg [Better care workers. A vision of the future of occupational health care]. Den Haag: SociaalEconomische Raad [The Social and Economic Council of the Netherlands]; 2014.

30. Blonk RWB, Brenninkmeijer V, Lagerveld SE, Houtman ILD. Return to work: a comparison of two cognitive behavioural interventions in cases of work-related psychological complaints among the self-employed. Work Stress. 2006;20:129-44.
31. van der Klink JJL, Ausems CMM, Beijderwellen BD, Blonk R, Bruinvels DJ, Dogger J et al. Achtergronddocument bij Richtlijn: Handelen van de berdijfsarts bij werkenden met psychische problemen [Background paper to Guideline: The management of mental health problems of workers by occupational physicians]. Utrecht: NVAB [Netherlands Society of Occupational Medicine]; 2007.

32. Arends I, van der Klink JJ, van Rhenen W, de Boer MR, Bultmann U. Prevention of recurrent sickness absence in workers with common mental disorders: results of a cluster-randomised controlled trial. Occup Environ Med. 2014;71(1):21-9. doi:10.1136/ oemed-2013-101412.

33. Volker D, Zijlstra-Vlasveld MC. Effectiveness of a blended webbased intervention on return to work for sick-listed employees with common mental disorders: results of a cluster randomized controlled trial. 2015;17(5):e116. doi:10.2196/jmir.4097.

34. Vlasveld MC, van der Feltz-Cornelis CM, Ader HJ, Anema JR, Hoedeman R, van Mechelen W, et al. Collaborative care for sicklisted workers with major depressive disorder: a randomised controlled trial from the Netherlands Depression Initiative aimed at return to work and depressive symptoms. Occup Environ Med. 2013;70(4):223-30. doi:10.1136/oemed-2012-100793.

35. Noordik E, van der Klink JJ, Geskus RB, de Boer MR, van Dijk FJ, Nieuwenhuijsen K. Effectiveness of an exposure-based return-to-work program for workers on sick leave due to common mental disorders: a cluster-randomized controlled trial. Scand J Work Environ Health. 2013;39(2):144-54. doi:10.5271/sjweh. 3320.

36. Martin MH, Nielsen MB, Madsen IE, Petersen SM, Lange T, Rugulies R. Effectiveness of a coordinated and tailored return-towork intervention for sickness absence beneficiaries with mental health problems. J Occup Rehabil. 2013;23(4):621-30. doi:10. 1007/s10926-013-9421-5.

37. Bakker IM, van Marwijk HWJ, Terluin B, Anema JR, van Mechelen W, Stalman WAB. Training GP's to use a minimal intervention for stress-related mental disorders with sick leave (MISS): Effects on performance: Results of the MISS project; a cluster-randomised controlled trial [ISRCTN43779641]. Patient Educ Couns. 2010;78(2):206-11.

38. Douwes M, Hooftman W, Kraan K, Steenbeek R, Venema A, de Vroome E, et al. Arbobalans 2014. Kwaliteit van de arbeid, effecten en maatregelen in Nederland [Quality of work, effects and measures in The Netherlands]. Leiden: TNO; 2014. p. 2014. 